
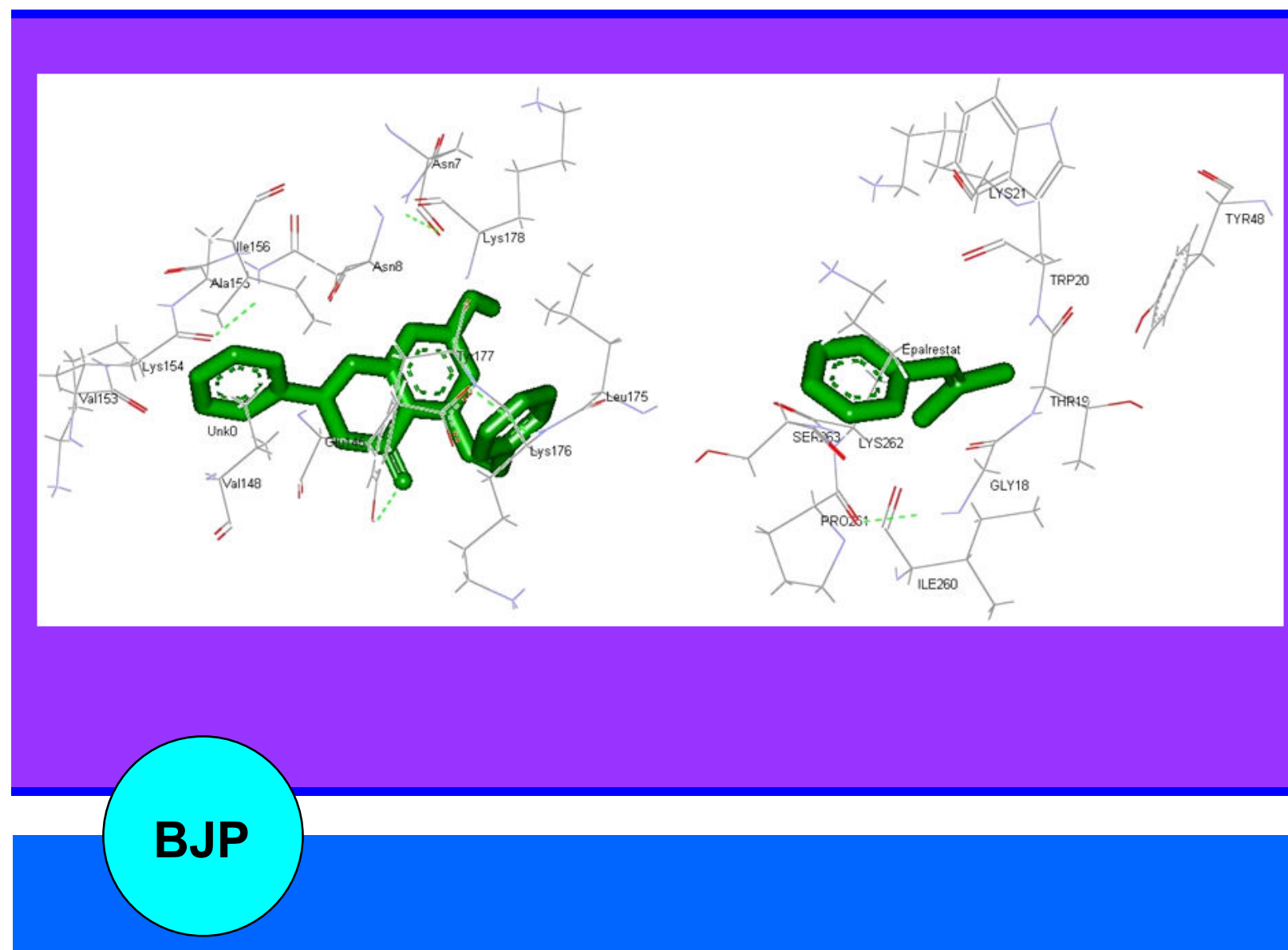

Bangladesh Journal of Pharmacology

Research Article

Docking studies: In silico aldose reductase inhibitory activity of commercially available flavonoids 
Abstracted/indexed in Academic Search Complete, Asia Journals Online, Bangladesh Journals Online, Biological Abstracts, BIOSIS Previews, CAB Abstracts, Current Abstracts, Directory of Open Access Journals, EMBASE/Excerpta Medica, Google Scholar, HINARI (WHO), International Pharmaceutical Abstracts, Open J-gate, Science Citation Index Expanded, SCOPUS and Social Sciences Citation Index;

ISSN: $1991-0088$

\title{
Docking studies: In silico aldose reductase inhibitory activity of commercially available flavonoids
}

\author{
Muthuswamy Umamaheswari, C. S. Aji, Kuppusamy Asokkumar, Thirumalaisamy \\ Sivashanmugam, Varadharajan Subhadradevi, Puliyath Jagannath and Arumugam \\ Madeswaran
}

Department of Pharmacology, College of Pharmacy, Sri Ramakrishna Institute of Paramedical Sciences, Coimbatore, Tamil Nadu, India.

\begin{tabular}{|c|c|}
\hline \multicolumn{2}{|l|}{ Article Info } \\
\hline Received: & 27 May 2012 \\
\hline Accepted: & 4 June 2012 \\
\hline Available Online: & 13 June 2012 \\
\hline \multicolumn{2}{|c|}{ DOI: 10.3329/bjp.v7i2.10779 } \\
\hline $\begin{array}{l}\text { Cite this article: } \\
\text { Umamaheswari } \\
\text { mar K, Sivasha } \\
\text { hadradevi V, Jaga } \\
\text { ran A. Docking stı } \\
\text { reductase inhibito } \\
\text { mercially availabl } \\
\text { ladesh J Pharmaco }\end{array}$ & $\begin{array}{l}\text { CS, Asokku- } \\
\text { am T, Sub- } \\
\text { P, Madeswa- } \\
\text { In silico aldose } \\
\text { tivity of com- } \\
\text { onoids. Bang } \\
\text { 2; } 7 \text { : 108-13. }\end{array}$ \\
\hline
\end{tabular}

\begin{abstract}
New drugs for the inhibition of the enzyme aldose reductase are in development and they have to be screened before being considered for preclinical and clinical evaluation. The current study deals with the evaluation of the cyclooxygenase inhibitory activity of flavonoids using in silico docking studies. In this perspective, flavonoids like bergapten, buceracidin-B, dorsilurin-F, communin-A, and coumestrol were selected. Epalrestat, a known aldose reductase inhibitor was used as the standard. Docking results showed that all the selected flavonoids showed binding energy ranging between -7.9 to $-5.1 \mathrm{kcal} / \mathrm{mol}$ when compared with that of the standard $(-5.6 \mathrm{kcal} / \mathrm{mol})$. Intermolecular energy $(-9.1$ to $-8.7 \mathrm{kcal} / \mathrm{mol})$ and inhibition constant $(1.6$ to $187.4 \mu \mathrm{M})$ of the ligands also coincide with the binding energy. Communin-A contributed better aldose reductase inhibitory activity because of its structural parameters.
\end{abstract}

\section{Introduction}

The drug discovery is a complex process whereby drugs are designed or discovered. The drug discovery in the past was a more tedious process that involved the identification of active constituents from traditional medicines or by serendipitous discovery.

The number of compounds entering the drug discovery process at the initial stage is usually very high. Among these only a very few candidate molecules makes it to the final step and emerges as the potential new therapy. The failure of a candidate molecule may occur due to different factors such as poor pharmacokinetics, lack of efficacy, adverse effects, commercial reasons etc. (Dias and Azevedo, 2008).

The AutoDock offers different types of search algorithms to search the conformational space. Among these, the Genetic Algorithm is the most modern and sophisti- cated. Genetic Algorithms are a family of powerful mathematical functions derived from the con-cepts of language of molecular genetics. The conditions in a biological evolution process are simulated and the conformational space is searched by "mutating" a ligand in order to find its lowest energy conformation in the "environment" of a fixed protein. Other types of search algorithms in AutoDock includes Simulated Annealing and Local Search (Morris et al., 2009; Hetenyi et al., 2002).

Aldose reductase (ALR2; EC: 1.1.1.21) belongs to aldoketo reductases super family. It is the first rate limiting enzyme in polyol pathway and reduces glucose to sorbitol by utilizing NADPH as a cofactor. Sorbitol dehydrogenase is the enzyme responsible for the conversion of Sorbitol into fructose (Ravindranath et al., 2009; Hwang et al., 2005). The polyol pathway represents a minor route of glucose utilization, accounting for less 


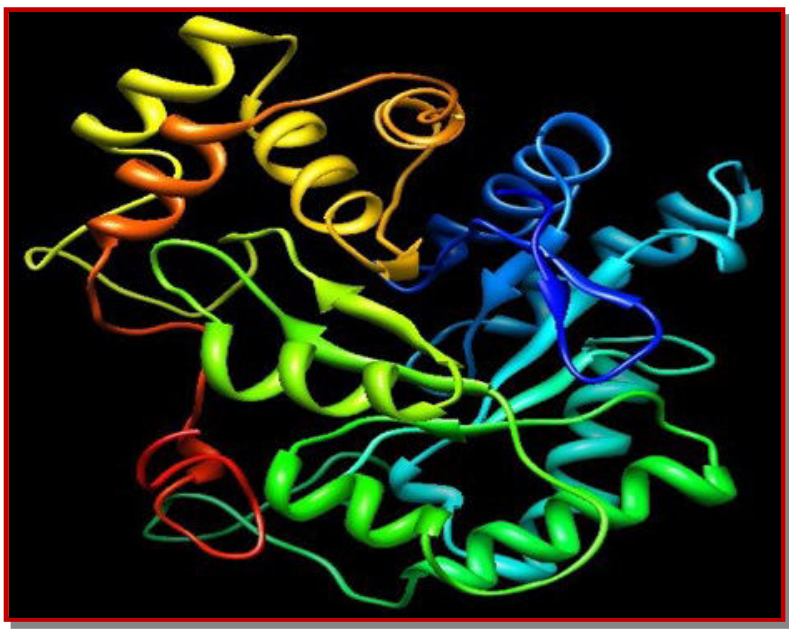

Figure 1: Refined aldose reductase enzyme from RCSB (3RX3)

than $3 \%$ of glucose consumption. However, in the presence of high glucose, the activity of this pathway is increased and could represent up to $30 \%$ of total glucose consumption (Yadav et al., 2009). Evidence for the involvement of ALR2 in diabetic neuropathy, retinopathy, nephropathy and cataract emerged from several independent studies (Guzman and Guerrero, 2005). Abnormal activation of the polyol pathway during diabetes leads to accumulation of osmotically active sorbitol leading to osmotic as well as oxidative stress, resulting in tissue injury (Dong et al., 2005; Saraswat et al., 2008 ).

Flavonoids are natural substances with variable phenolic structures which are widely distributed in fruit, vegetables, grains, bark, roots, stems, flowers, tea, and wine. Over 4,000 structurally different flavonoids have been discovered from plant sources. These have raised considerable interest recently because of their beneficial effects on human health and are found to have antiviral, anti-allergic, antiplatelet, anti-inflammatory, anti-tumor and anti-oxidant activities. Research done on flavonoids led to the discovery of the French paradox, ie, low incidence of coronary heart disease, despite having a diet relatively rich in Mediterranean populations in association with red wine consumption and a high saturated fat intake (Patel, 2008).

The stereochemistry of binding of the flavonoids on aldose reductase has not yet been characterized. In the present study, the structural models of the ligands in the aldose reductase binding sites has been carried out, which may facilitate further development of more potent anti diabetic agents.

\section{Materials and Methods}

\section{Software required}

Python 2.7- language was downloaded from www.python.com, Cygwin (a data storage) c: \program and Python 2.5 were simultaneously downloaded from www.cygwin.com, Molecular graphics laboratory (MGL) tools and AutoDock4.2 was downloaded from www.scripps.edu, Discovery studio visualizer 2.5.5 was downloaded from www.accelerys.com, Molecular orbital package (MOPAC), Chemsketch was downloaded from www.acdlabs.com. Online smiles translation was carried out using cactus.nci.nih.gov/translate/.

\section{Docking methodology}

Lamarckian genetic algorithm (LGA) for ligand conformational searching, which is a hybrid of a genetic algorithm and a local search algorithm was employed in present study. This algorithm first builds a population of individuals (genes), each being a different random conformation of the docked molecule. Each individual is then mutated to acquire a slightly different translation and rotation and the local search algorithm then performs energy minimizations on a user-specified proportion of the population of individuals. The individuals with the low resulting energy are transferred to the next generation and the process is then repeated. The algorithm is called Lamarckian because every new generation of individuals is allowed to inherit the local search adaptations of their parents.

An extended PDB format, termed as PDBQT file was used for coordinate files which includes atomic partial charges. AutoDock Tools was used for creating PDBQT files from traditional PDB files (Madeswaran et al., 2011). Crystal structure of aldose reductase enzyme was downloaded from the Brookhaeven protein data bank and refined with the help of Accelrys studio viewer (Figure 1).

The flavonoid ligands like bergapten, buceracidin-B, dorsilurin-F, communin-A, coumestrol and epalrestat were built using Chemsketch and optimized using "Prepare Ligands" in the AutoDock 4.2 for docking studies. The optimized ligand molecules were docked into refined aldose reductase model using "LigandFit" in the AutoDock 4.2 (Goodsell et al., 1996).

The preparation of the target protein $3 \mathrm{RX} 3$ with the AutoDock Tools software involved adding all hydrogen atoms to the macromolecule, which is a step necessary for correct calculation of partial atomic charges. Gasteiger charges are calculated for each atom of the macromolecule in AutoDock 4.2 instead of Kollman charges which were used in the previous versions of this program. Three-dimensional affinity grids of size $277 \times 277 \times 277 \AA$ with $0.6 \AA$ spacing were centered on the geometric center of the target protein and were calculated for each of the following atom types: HD, C, A, N, OA, and SA, representing all possible atom types in a protein. Additionally, an electrostatic map and a desolvation map were also calculated (Konc et al., 2011). Rapid energy evaluation was achieved by 
precalculating atomic affinity potentials for each atom in the ligand molecule. In the AutoGrid procedure, the target enzyme was embedded on a three dimensional grid point (Umamaheswari et al., 2011). The energy of interaction of each atom in the ligand was encountered.

We have selected important docking parameters for the LGA as follows: Population size of 150 individuals, 2.5 million energy evaluations, maximum of 27000 generations, number of top individuals to automatically survive to next generation of 1 , mutation rate of 0.02 , crossover rate of 0.8, 10 docking runs, and random initial positions and conformations. The probability of performing local search on an individual in the population was set to 0.06 .

AutoDock was run several times to get various docked conformations, and used to analyze the predicted docking energy. The binding sites for these molecules were selected based on the ligand-binding pocket of the templates. AutoDock Tools provide various methods to analyze the results of docking simulations such as, conformational similarity, visualizing the binding site and its energy and other parameters like intermolecular energy and inhibition constant. For each ligand, ten best poses were generated and scored using AutoDock 4.2 scoring functions (Madeswaran et al., 2012).

\section{Results and Discussion}

In silico docking study, was carried out to identify the inhibiting potential of selected flavonoids against aldose reductase enzyme (Figure 2). Lead optimization of the selected compounds was done by computation of druglikeness properties. The druglikeness scores of the compounds were evaluated with the help of Lipinski's rule. The docking studies were performed by the use of AutoDock 4.2. In the docking studies, if a compound shows lesser binding energy compared to the standard it proves that the compound has higher activity.

The docking poses were ranked according to their docking scores and both the ranked list of docked ligands and their corresponding binding poses (Sivakumar et al., 2011). In Figure 3, docked pose of aldose reductase enzyme with the ligands communin-A and Epalrestat clearly demonstrated the binding positions of the ligand with the enzyme. Binding energy of the individual compounds were calculated using the following formula,

Binding energy $=\mathrm{A}+\mathrm{B}+\mathrm{C}-\mathrm{D}$

Where, A denotes final intermolecular energy + van der Walls energy (vdW) + hydrogen bonds + desolvation energy + electrostatic energy $(\mathrm{kcal} / \mathrm{mol})$, B denotes final total internal energy $(\mathrm{kcal} / \mathrm{mol}), \mathrm{C}$ denotes torsional free energy $(\mathrm{kcal} / \mathrm{mol}), \mathrm{D}$ denotes unbound system's energy (kcal/mol).
Analysis of the receptor/ligand complex models generated after successful docking of the flavonoids was based on the parameters such as hydrogen bond interactions, $\ddot{i}-\dddot{i}$ interactions, binding energy, RMSD of active site residues and orientation of the docked compound within the active site (Azam et al., 2011). As a general rule, in most of the potent anti inflammatory compounds, both hydrogen bond and $\ddot{i}-\ddot{i}$ hydrophobic interactions between the compound and the active sites of the receptor have been found to be responsible for mediating the biological activity.

The potential binding sites of the communin-A was found that, ASN 7, ASN 8, GLU 145, VAL 148, VAL 153, LYS 154, ALA 155, ILE 156, LEU 175, LYS 176, TYR 177 and LYS 178. The binding sites of the epalrestat was found to be GLY 18, THR 19, TRP 20, LYS 21, SER 210, PRO 211, LEU 212, SER 214, ILE 260, PRO 261, LYS 262 and SER 263. This proves that the effective binding sites are present in the selected flavonoid communin-A when compared with the standard epalrestat. It proves that the ability of inhibiting the aldose reductase enzyme by the selected compounds.

Flavonoids showed binding energy ranging between $7.91 \mathrm{kcal} / \mathrm{mol}$ to $-5.08 \mathrm{kcal} / \mathrm{mol}$ (Table I). From the selected flavonoids communin-A had showed better binding energy $(-3.93 \mathrm{kcal} / \mathrm{mol})$ when compared to the standard epalrestat $(-5.59 \mathrm{kcal} / \mathrm{mol})$. This proves that communin-A consist of potential aldose reductase inhibitory binding sites when compared to the standard.

In addition, two other parameters like inhibition constant $\left(\mathrm{K}_{\mathrm{i}}\right)$ and intermolecular energy were also determined. Inhibition constant is directly proportional to binding energy. Theoritical $\mathrm{IC}_{50}$ was calculated with the help of AutoDock 4.2. Flavonoids showed inhibition constant ranging from 1.6 to $187.4 \mu \mathrm{M}$ (Table II). Communin-A had better inhibition constant $(1.6 \mu \mathrm{M})$ when compared to the standard $(80.1 \mu \mathrm{M})$. This implies that the communin-A were found to be higher activity against aldose reductase enzyme when compared to Epalrestat. We found a decrease in inhibition constant of all the selected flavonoids with a simultaneous decrease in the binding energy.

Intermolecular energy is also directly proportional to binding energy. We found a decrease in intermolecular energy of all the selected compounds with a simultaneous decrease in the binding energy. Flavonoids showed intermolecular energy ranging between -9.1 to $8.7 \mathrm{kcal} / \mathrm{mol}$ (Table III).

Communin-A had better intermolecular energy (-9.1 $\mathrm{kcal} / \mathrm{mol})$ when compared to the standard $(-5.6 \mathrm{kcal} /$ $\mathrm{mol})$. This result further proved that communin-A consist of better aldose reductase inhibitory activity compared to the standard. 


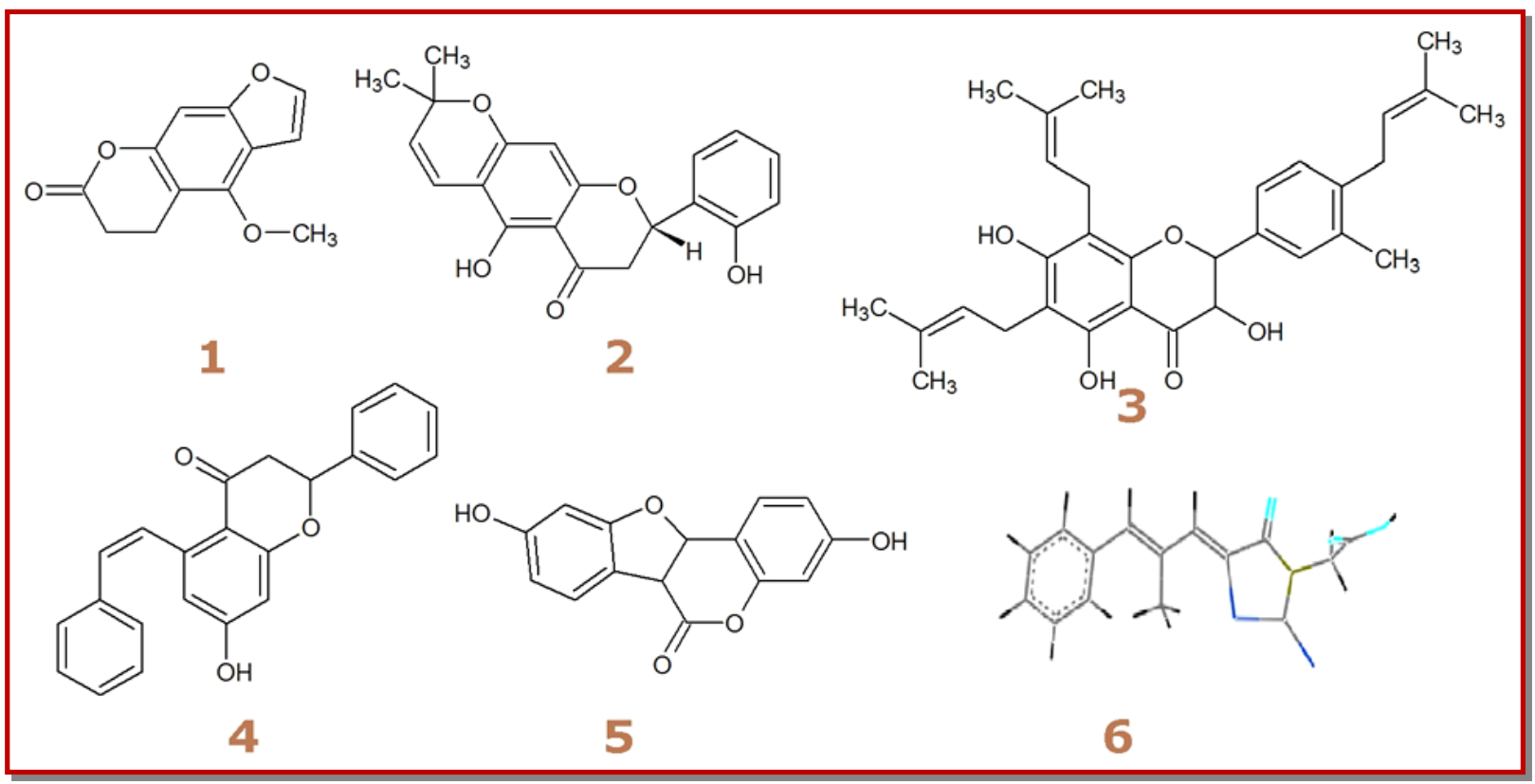

Figure 2: The optimized ligand molecules (1 Bergapten, 2 Buceracidin-B, 3 Dorsilurin-F, 4 Communin-A, 5 Coumestrol, and 6 Epalrestat)

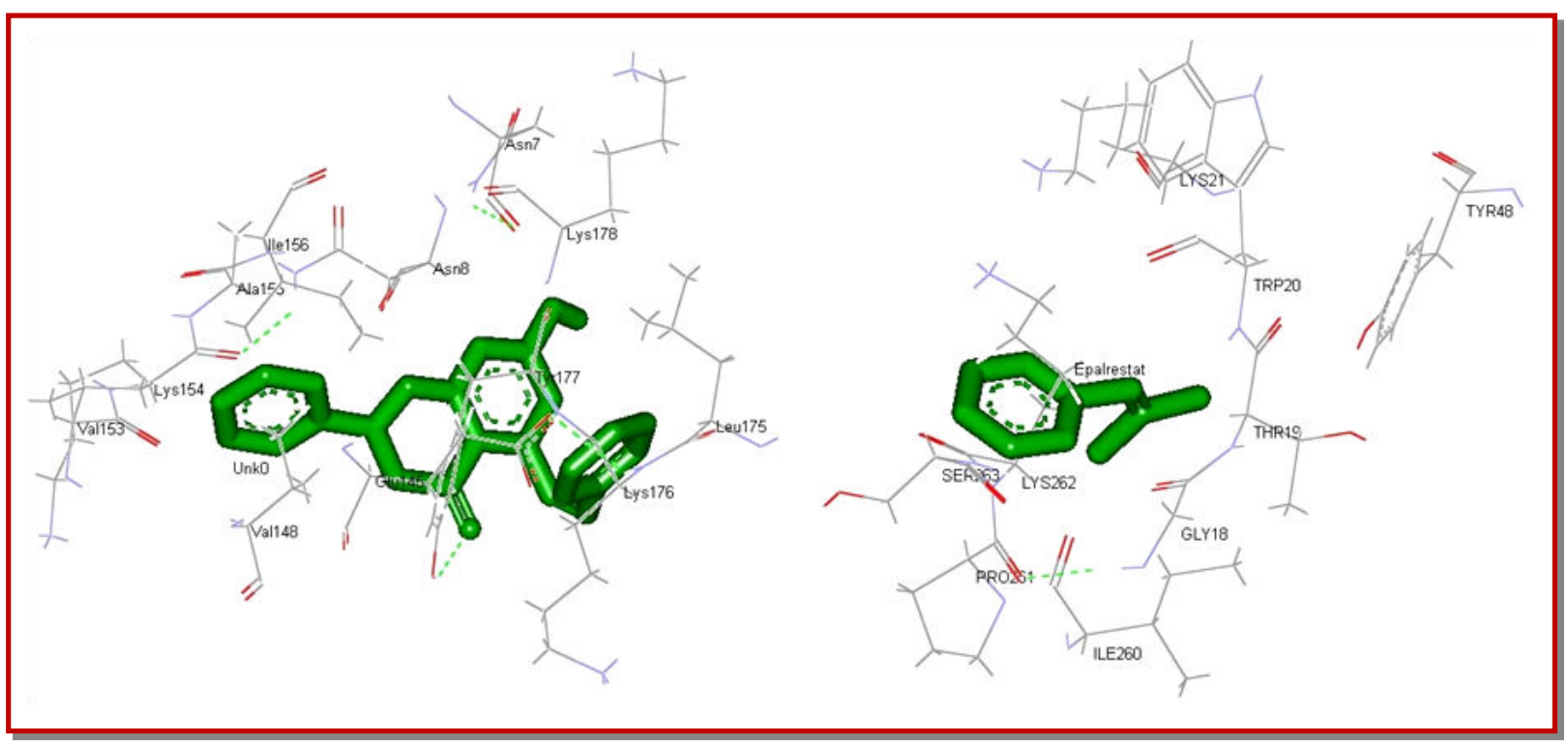

Figure 3: Docked pose of aldose reductase enzyme (3RX3) with communin-A and epalrestat

Based on the docking studies, the aldose reductase inhibitory activity of the selected compounds was found to be decreased in the order of communin-A, buceracidin-B, coumestrol, Bergapten, epalrestat, and dorsilurin-F. All the flavonoids possess binding sites with aldose reductase enzyme. But, only the communin -A showed better binding interactions and docking parameters (binding energy, inhibition constant, intermolecular energy) than the other selected flavonoids and the standard.

On the basis of the above study, communin-A, possess potential aldose reductase inhibitory binding sites and docking parameters compared to that of the standard. This may be attributed due to the differences in the position of the functional groups in that compound. Further development of communin-A and their derivatives could be a potential drug candidate for the aldose reductase inhibition in future.

\section{Conclusion}

These results indicate that selected flavonoids, 


\section{Table I}

Binding energies of the compounds based on their rank

\begin{tabular}{|c|c|c|c|c|c|c|c|c|c|c|}
\hline \multirow[t]{2}{*}{ Compound } & \multicolumn{10}{|c|}{ Binding energies of the compounds based on their rank $(\mathrm{kcal} / \mathrm{mol})$} \\
\hline & 1 & 2 & 3 & 4 & 5 & 6 & 7 & 8 & 9 & 10 \\
\hline Bergapten & -5.7 & -5.7 & -5.7 & -5.7 & -5.7 & -5.7 & -5.7 & -5.7 & -5.7 & -5.7 \\
\hline Buceracidin-B & -6.8 & -6.8 & -6.1 & -6.6 & -6.5 & -6.4 & -6.4 & -6.4 & -6.4 & -5.7 \\
\hline Dorsilurin-F & -5.1 & -4.8 & -4.8 & -4.7 & -4.3 & -4.1 & -4.0 & -3.8 & -3.5 & -3.3 \\
\hline Communin-A & -7.9 & -7.8 & -7.8 & -7.8 & -6.6 & -6.6 & -6.4 & -6.2 & -5.6 & -5.6 \\
\hline Coumestrol & -6.6 & -6.6 & -6.6 & -6.6 & -6.6 & -6.6 & -6.6 & -6.5 & -6.5 & -6.5 \\
\hline Epalrestat & -5.6 & -5.6 & -5.6 & -5.6 & -5.6 & -5.6 & -5.6 & -5.6 & -5.6 & -5.6 \\
\hline
\end{tabular}

Table II

Inhibition constant of the compounds based on their rank

\begin{tabular}{|lrr|r|r|r|r|r|r|r|r|}
\hline & \multicolumn{8}{c|}{ Inhibition Constant of the compounds based on their rank $(\mu \mathrm{M}$, amM $)$} \\
\cline { 2 - 13 } Compound & 1 & 2 & 3 & 4 & 5 & 6 & 7 & 8 & 9 & 10 \\
Bergapten & 62.4 & 63.1 & 63.6 & 63.7 & 64.4 & 64.6 & 64.6 & 66.0 & 66.3 & 67.4 \\
Buceracidin-B & 9.5 & 10.2 & 33.7 & 13.9 & 16.3 & 20.3 & 19.1 & 20.2 & 20.4 & 63.1 \\
Dorsilurin-F & 187.4 & 322.1 & 324.4 & 381.0 & 749.2 & 950.2 & $1.05^{\mathrm{a}}$ & $1.61^{\mathrm{a}}$ & $2.5^{\mathrm{a}}$ & $4.0^{\mathrm{a}}$ \\
Communin-A & 1.6 & 1.8 & 1.8 & 1.8 & 13.6 & 14.9 & 20.7 & 27.6 & 72.7 & 76.2 \\
Coumestrol & 15.1 & 15.2 & 15.3 & 15.3 & 15.3 & 15.4 & 15.5 & 16.2 & 16.5 & 18.3 \\
Epalrestat & 80.1 & 80.8 & 81.1 & 81.3 & 81.5 & 82.9 & 82.9 & 83.0 & 83.5 & 83.7 \\
\hline
\end{tabular}

Table III

Intermolecular energies of the compounds based on their rank

\begin{tabular}{|lrr|r|r|r|r|r|r|r|r|}
\hline Compound & \multicolumn{8}{c|}{ Inter molecular energies of the compounds based on their rank (kcal/mol) } \\
\cline { 2 - 14 } & 1 & 2 & 3 & 4 & 5 & 6 & 7 & 8 & 9 & 10 \\
Bergapten & -6.0 & -6.0 & -6.0 & -6.0 & -6.0 & -6.0 & -6.0 & -6.0 & -6.0 & -6.0 \\
Buceracidin-B & -7.7 & -7.7 & -7.0 & -7.5 & -7.4 & -7.3 & -7.3 & -7.3 & -7.3 & -6.6 \\
Dorsilurin-F & -8.7 & -8.3 & -8.3 & -8.2 & -7.8 & -7.7 & -7.6 & -7.4 & -7.1 & -6.9 \\
Communin-A & -9.1 & -9.0 & -9.0 & -9.0 & -7.8 & -7.8 & -7.6 & -7.4 & -6.8 & -6.8 \\
Coumestrol & -7.2 & -7.2 & -7.2 & -7.2 & -7.2 & -7.2 & -7.2 & -7.1 & -7.1 & -7.1 \\
Epalrestat & -5.6 & -5.9 & -5.9 & -5.9 & -5.9 & -5.9 & -5.9 & -5.9 & -5.9 & -5.9 \\
\hline
\end{tabular}

communin-A have better binding sites and interactions with aldose reductase enzyme.

\section{References}

Azam F, Prasad MVV, Thangavel N. Molecular docking studies of 1-(substituted phenyl) -3- (naphtha [1,2-d] thiazol2 -yl) urea/thiourea derivatives with human adenosine A2A receptor. Bioinformation 2011; 6:330-34.

Dias R, Azevedo WF. Molecular docking algorithms. Curr Drug Targets. 2008; 9: 1040-47.

Dong Y, Yang J, Ren X, Zhang H, He J. New Aldose Reductase Inhibitors N99-596 A and B from Streptomyces. J Antibiotics
2005; 58: 737-39.

Goodsell DS, Morris GM, Olson AJ. Automated docking of flexible ligands: Applications of AutoDock. J Mol Recog. 1996; 9: 1-5.

Guzman A, Guerrero OR. Inhibition of aldose reductase by herbs extracts and natural substances and their role in prevention of cataracts. Revista Cubana de Plantas Medicinales, 2005; 10: 3-4.

Hetenyi C, Van der Spoel D. Efficient docking of peptides to proteins without prior knowledge of the binding site. Protein Sci. 2002; 11: 1729-37.

Hwang YC, Shaw S, Kaneko M. Aldose reductase pathway mediates JAK-STAT signaling: A novel axis in myocardial 
ischemic injury. J Fed Am Soci Exp Biol. 2005; 19: 795-97.

Konc J, Konc JT, Penca M, Janezic D. Binding-sites prediction assisting protein-protein docking. Acta Chim Slov. 2011; 58: 396-401.

Madeswaran A, Umamaheswari M, Asokkumar K, Sivashanmugam T, Subhadradevi V, Jagannath P. In Silico docking studies of lipoxygenase inhibitory activity of commercially available flavonoids. J Comput Method Mol Design. 2011; 1: $65-72$.

Madeswaran A, Umamaheswari M, Asokkumar K, Sivashanmugam $\mathrm{T}$, Subhadradevi $\mathrm{V}$, Jagannath $\mathrm{P}$. In silico docking studies of lipoxygenase inhibitory activity of commercially available flavonoids. Orient Pharm Exp Med. 2012; 12: 15761.

Morris GM, Huey R, Lindstrom W, Sanner MF, Belew RK, Goodsell DS. AutoDock 4 and AutoDockTools 4: Automated docking with selective receptor flexibility. J Computational Chem. 2009; 30: 2785-91.

Patel JM. A review of potential health benefits of flavonoids. Lethbridge Undergraduate Res J. 2008; 3: 1-5.
Ravindranath TM, Mong PY, Ananthakrishnan R. Novel role for aldose reductase in mediating acute inflammatory responses in the lung. J Immunol. 2009; 183: 8128-37.

Saraswat M, Muthenna P, Suryanarayana P, Petrash JM, Reddy G. Dietary sources of aldose reductase inhibitors: Prospects for alleviating diabetic complications. Asia Pacific J Clin Nut. 2008; 17: 558-65.

Sivakumar R, Lokesh N, Rajashekhar A, Ramu N, Saikishore P, Venkatanarayanan R. Docking studies on PPARY of novel aphenoxy phenyl propionic acid derivatives as antidiabetic agent. Der Pharmacia Sinica. 2011; 2: 327.

Umamaheswari M, Madeswaran A, Asokkumar K, Sivashanmugam T, Subhadradevi V, Jagannath P. Study of potential xanthine oxidase inhibitors: In silico and in vitro biological activity. Bangladesh J Pharmacol. 2011; 6: 117-23.

Yadav UC, Naura AS, Aguilera AL. Aldose reductase inhibition suppresses the expression of Th2 cytokines and airway inflammation in ovalbumin-induced asthma in mice. J Immunol. 2009; 183: 4723-32. 